\title{
Positive Psychologists on Positive Psychology: Nic Marks
}

\author{
Interview by \\ Aaron Jarden
}

\begin{abstract}
Nic Marks is a recognised expert in the field of wellbeing research and positive psychology, and undertakes innovative research in the use of wellbeing indicators in public policy environments. Nic founded the New Economics Foundation's 'Centre for Wellbeing' and has led the wellbeing programme at the New Economics Foundation since 2001. This has included creating the very influential 'Five Ways to Wellbeing' campaign which now has global reach.
\end{abstract}

\section{What prompted your interest in positive psychology?}

I came to positive psychology to try to unpick the question around sustainable development, which is how we try to create for people good lives that don't cost the earth. It became fairly obvious that we need to think more about the quality of life than the quantity of life, trying to unpack the difference between economic growth and quality. So, I came to the field of the science of wellbeing, international quality of life studies, and latterly positive psychology, to work out whether we could measure that experience of life because that seems to me critical in how we re-vision what the future should be.

\section{And you've been in the field for a while?}

I've been in the field of thinking about alternative indicators of GDP for about 20 years, but wellbeing and subjective wellbeing for some 10 years now, since about 2001.

What would you say are some of the most distinctive features of positive psychology and how it applies to what you're doing?

Firstly, it's a great, fun, topic and it's very appealing to people. We've had so much psychology that's been about fixing the bad things, which obviously is important, but I think there's been a lack of giving people the opportunity to fulfil themselves - so positive psychology is great for that reason. And then there's some good science coming out, showing that wellbeing is not exactly the opposite of ill-being, and I think that that is interesting. Barbara Frederickson's work is standout work in the positive psychology area.

So when you think about the big questions that the field of positive psychology addresses, what would you say those questions are?

How do lives go well? What are the causes of lives going well? How can we define that and how can we improve people's lives? Ultimately it's about making a difference. Positive

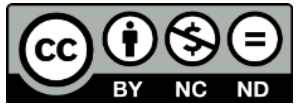

Copyright belongs to the author(s) www.internationaljournalofwellbeing.org 
psychology is about making a difference, an improvement to people's lives and I think that's positive psychology's aim. It's a noble aim.

\section{What's a social justice issue that positive psychology should focus on, in your view?}

This is a developed world social justice issue. There are developing world social justice issues as well, but we know that people at the bottom of the income spectrum have lower happiness, wellbeing, than people further up it. But what positive psychology shows us, if you actually unpick it a bit, is that money is not the only causal thing that is going to get them out of that. So it's not about throwing benefits and such things to those at the lower end of the income spectrum, it's actually about giving them a sense of agency, and actually getting them to critically and wholly participate in society, or helping them to participate-'getting' them to participate is too strong. It's not about being prescriptive, it's more about facilitating that process, and so they're not activating the sort of things we know about that bring people wellbeing. That's because they don't have that capacity to support, they haven't had that love and care. So positive psychology reframes the issue of inequalities into an inequality of agency, rather than an inequality of money.

\section{What do you think is the best way for them to achieve that?}

Who? Policy makers or people individually?

\section{Both, really. I mean that is the problem and if you had unlimited ways to fix it, how would you go about fixing it?}

Right at the bottom of the income spectrum needs to have funded interventions because you'll then have future benefits. That would actually save the government a lot of money. Those interventions might be in part financial, but they'd be more things such as access to small micro credit loans and things like that. But they also need to be about getting social support and mentoring and helping people learn, not necessarily formal learning, but learning from others in their community. Communities can work together and actually release passion and interest; and engagement in them is very, very interesting. Most of these people couldn't even begin to think about how to set up a small business or something like that. Yet they have skills and passions and interests and strengths: but how do you release them? So it's a very facilitative approach, which is unusual for government. Government usually tends to be happier if it's building things or putting in place infrastructure, physical things. So it's quite a different sort of a process.

\section{It seems from what you're saying it needs to be a bit of top down, but also has to be a bit of bottom up, for those 'bottom rung' people?}

Yes, you can't tell someone what their passions should be. You've got to have a conversation about that. So, the 'top down' needs to be putting facilitators and coaches into these communities. Rather than building community centres, actually pay for these people to live in the community and to get to know the community and find out how they can get to work with people and have a very free remit to do that. And maybe setting up small funds that people can dip into to borrow that first 200 pounds or whatever to set up something small. There are really big returns on investment for those sorts of projects. 


\section{So it's more about a hand-up than a hand-out?}

Yes, the process has to be bubbling up rather than trickling down. It has to be using people's energy and releasing that in their communities.

\section{What do you think are some of the most valid criticisms of positive psychology?}

There have been far too many claims made far too quickly about certain interventions. The press have got very excited about it, and people have over-claimed success. Quite a lot of the claims made can come across as too theory-led or they haven't actually done enough to enable people to use it. On other occasions they are too focussed on specific interventions that can be proved in clinical studies, in rigorous trials and blind studies and that sort of thing. That's all fine, but we have to generalise out from that if we are really going to make it useful. So, you want to have the science and you want to be able to go from that, so you want to be able to use the social marketing techniques. We need to be able to communicate things better. So, counting your blessings is great, but it's not going to be an intervention that saves the world, and gratitude letters are not going to either. Also, claims of universality across all cultures, when they're quite culturally specific, have been a problem. But, generally, I think that the field of positive psychology is doing a great amount of human good.

\section{What's the one thing that brings your work to the attention of others?}

One of the things we do well at NEF is communicating, and by that I mean taking relatively complex ideas and presenting them in ways that are simple, but not simplistic. That's the aim. We do some good work, and some of it is less good than other parts; but you know when something is good, that's when it travels and people start using it. There are a few things that we have done that have really travelled. The 'Happy Planet Index' and 'Five Ways to Wellbeing' are two examples, but there are others as well-and these are things we have tried to simplify, without making them too simplistic.

I liked what you said once about starting with the people and then working backwards, and I don't think many people think that way at all and that's where the application of the science breaks down...

Yeah, you can see that there are lots of people that want to coach in positive psychology, and this is not to say that there are not ways to make money out of positive psychology, but it would be nicer if it was a bit more focussed on human good and less on individual ways to set up consultancies. That is somewhat problematic and is reflected in the fact that we have a very poor ethnic mix of people coming to positive psychology conferences -it's pretty much all European Americans. People are not going to be naturally attracted to positive psychology, and the positive psychology community is going to have to work very hard. There should be a conscious effort to attract a broad range of people to positive psychology.

\section{In what ways do people make money out of the field of positive psychology?}

There is a lot of business consultancy, and there is nothing wrong with business consultancy. People need to be able to make money. But there has been too much focus on how that happens sometimes. 


\section{Who do you look up to in the field of positive psychology?}

Ed Diener. He is a fantastic empiricalist. He has taken risks in his career and I think he is outstanding. John Helliwell, because he brings the social into it. He understands how communities work and understands the importance of how that works in that context. Barbara Frederickson is a great experimental psychologist and has a great ability to communicate really well. Her work has a really good grounding in science. They would be my top three.

Have you made any big mistakes, or do you have any regrets, in your progress as you have moved into the positive psychology field? Things that you look back on and think "I really should not have done that!"?

Not regrets; of course you make mistakes and think about how you could have done things better, but that's your learning process. When I came to the field in 2001, in the early days, I was learning here. I'm not a psychologist, I'm a statistician and a psychotherapist, but that's not a technical psychologist, so clearly in the first projects we did we had questionnaires that were too long, because we didn't understand enough about them, but you learn from that, so I don't think that there are any regrets with that.

There are the established people in positive psychology who are really well known. Are there any people who stick out for you, who aren't well known, who are emerging, at the cutting edge of the science, who you'd like to flag for the future?

Joar Vitterso from Norway. I don't know if you have heard of him, but he's doing good work on interest and also curiosity as well. Looking at how there are different types of positive emotions that may have previously been put into one bracket, suggesting that they all behave the same way, whereas actually they don't. For example, pleasure does not operate the same way as enthusiasm or engagement; and how do we start to differentiate between some of the positive emotions and their effects on people? So his work is very interesting.

An under-thought about a field in positive psychology is genes and environment interplay. We haven't seen nearly enough work on that, and it's quite technical work; but it's really important. We need to know how we intervene with people, and if we're thinking that the environment and the interventions in the environment are going to work the same for all people-that's rubbish. So, we need to know much more about genetically informed datasets, and particularly around interventions with children.

Over the last three or four years, of all the books you've read about positive psychology, what's the one that stood out to you, changed your mind, as being fresh, the most inspirational book in the area of positive psychology?

A book is hard because I read Barbara Fredrickson's book Positivity and I actually think that I preferred some of Barbara's papers, but that's just me. It's like Sonya Lyubomirsky's book The How of Happiness; it's fine but it didn't really inspire me. I guess that Barry Schwartz's books [The Paradox of Choice and The Loss of Wisdom] really stuck out to me. I'd put him up there with someone who I enormously respect, he's challenged the positive psychology movement and challenged the VIA strengths and how they are defined, and he's very smart. So probably his was the book I really went 'wow' at, although that's probably about six years old now. 
What book would you recommend to someone who doesn't know anything about the field of positive psychology? When they find out about positive psychology, what's the first book they should read?

The one I normally recommend is Positive Psychology in a Nutshell by Ilona Boniwell, which is just a small book, about 100 pages, which is succinct, but probably needs updating now, although I realise she also has a new textbook on positive psychology just out. In the past I have quite strongly recommended Authentic Happiness, because it is good for the field. And then there's Flourish...

\section{Thinking of the current concerns in the field of positive psychology, what two concerns} would you list as most needing to be addressed in order to make positive psychology a better discipline going forward?

Firstly, it needs to address its cultural bias, its ethnic bias. That's critical. Secondly it needs to think climate change and think about the environment. I find it so shocking that there are no tracks on interaction between nature and positive psychology. You can take it very softly, for example there's nothing looking at human beings and just how it feels to be outside. I know there is an article that's just come out in the International Journal of Wellbeing that focuses on nature, context and human wellbeing and uses Central Park in New York as an example and we need more of that kind of stuff. It's really important that we understand that there is a huge contextual impact in how the environment impacts on people, and that it's not all individually based. It's important to positive psychology to get out of the individual, and into the social.

\section{What do you think are the pros and cons about the main governing body, IPPA?}

It's too American-based: this conference [the $2^{\text {nd }}$ World Congress on Positive Psychology] was supposed to be in Europe, but they didn't take the risk to do that. I also think it's too narcissistic in a way, too inward turning. For example, to give six fellowships to six of the almost founding fathers of positive psychology. So you found an organisation and then get awarded by it? They should have given Barbara [Fredrickson], or Sonya [Lyubomirsky], or Todd [Kashdan], or Tim Kasser, people who are doing really good research in different areas, these awards. They should be using the organisation to give people a leg up in the field, not to go "jolly well done". There are lots of pros to IPPA though; I don't want to say it's not a good organisation. There is a lot that needs to be debated though. There are a lot of really good people involved here and there is a really interesting scientific base. The International Positive Psychology Association should also be a bit stricter about the empirical robustness of work sometimes-although it's better than five years ago when people used to give papers on positive psychology. It's improved a lot.

\section{What discipline do you think positive psychology can learn the most from, moving forward as an early science?}

It needs to learn more from systems theory, complexity. It's too linear sometimes. It could learn more from social psychology, just generally, get out of the individual. The European tradition in psychology is more social and cultural. Also, probably evolutionary psychology. Barbara [Fredrickson] does this very well, whereas PERMA does not really have an evolutionary story behind it. Ed Diener is much clearer that he thinks life satisfaction is the best measure; now, you can agree or disagree with that, but he has a stance on that. 
What do you think about the distinction 'pushed from the past and pulled into the future' as a point for positive psychologists to focus on or think more about?

I have not really digested what Marty [Seligman] said about that in a lot of ways yet, but I do think he's right to think that there's a distinction between reminiscing about the past and anticipating about the future, and that views about the future are very much influence by the now. We don't need to be as much weighed down by the past as psychodynamic theory has told us to be. For example, people don't necessarily need to delve into the past to explain their present quite so much. I like the way that positive psychology is an optimistic science and does include things about the future too. Psychotherapy and counselling is often not focussed enough on that, and I'm treating those as disciplines that have tried to improve the human lot, and they have done. But you should only think about the past in as much as it affects the present right now. Negativity gets you caught in patterns. Do I think that there is a pull from the future? It is very difficult scientifically to say that, but personally, yeah I do.

This is a book for people looking to move into the field of positive psychology. Is there anything else you'd like to comment on that I have not asked about?

Coming to positive psychology with an open mind has the potential for lots to be learned from it, as there is a lot to be learnt and discovered. It is an exciting discipline and I would like it to be linked more closely to social dimensions and cultural dimensions - which it is trying to do. Ultimately, I'd like it to start to help us tackle what are some of the most pressing issues of our day. The $21^{\text {st }}$ century is going to have to come to terms with the entrenched poverty in the world and how we deal with that, and climate change and how we dematerialise our economies. Positive psychology, although not many currently think this way, has a huge contribution to make towards that, because it looks at what makes life go well, and it gives us the freedom to think in a different way.

\section{Author}

Aaron Jarden

Open Polytechnic of New Zealand

aaron.jarden@openpolytechnic.ac.nz 